\title{
Assessing the Relationship and Prediction of Manifold Facets of Analytic Relations to Academic Reading Comprehension
}

\author{
Md Kamrul Hasan \\ English Language Institute, United International University, \\ Dhaka, Bangladesh \\ https:// orcid.org/0000-0003-2353-4673 \\ Md. Didar Hossain \\ English Language Institute, United International University \\ Dhaka, Bangladesh \\ https:// orcid.org/0000-0002-9509-6206 \\ Abdul Karim \\ BRAC Institute of Languages, BRAC University \\ Dhaka, Bangladesh \\ https://orcid.org/0000-0003-2488-8297
}

\begin{abstract}
A thorough investigation of analytic relations and their different dimensions by lexical researchers plays a prominent role in language learning and teaching. The current study aimed at investigating the association and prediction of multifarious dimensions of analytic relations of vocabulary knowledge to reading comprehension among 155 English as a Foreign Language (EFL) students at the tertiary level, employing standard multiple regression analysis under a quantitative approach. Ninety-one students from Business School and sixty-four Engineering students took part in six components, namely member-collection, stuff-object, component-integral, portion-mass, place-area, and feature-activity of one analytic relations test, and three multiple-choice passages of one academic reading comprehension task. The results showed that inter-correlations among all six aspects of analytic relations were positive and statistically significant; except correlation between stuff-object and reading comprehension, associations between the other five facets of analytic relations and academic reading comprehension were strong, positive and significant. Not only the component-integral analytic relations feature made statistically the most significant unique prediction but also it had the largest effect on academic reading comprehension.
\end{abstract}

Keywords: academic reading comprehension; analytic relations; correlation; vocabulary knowledge; prediction 


\section{Introduction}

More than three decades ago, vocabulary acquisition was treated as a neglected dimension of language teaching and learning (Meara, 1980). Recently, it has plausibly become one of the most substantial research niches in the second language (L2) acquisition, assessment, and instruction (Schmitt, 2010; Zhang \& Yang, 2016). Up till now, research on L2 vocabulary knowledge has evidenced a clear polarity regarding its multidimensionality (Zhang \& Yang, 2016). The significant role of vocabulary knowledge in L2 learning has been welldocumented (Choi \& Zhang, 2018; Nakata, Tada, Mclean \& Kim, 2020; Nation, 1983; Schmitt, 2008; Zhang, Lin, Zhang \& Choi, 2017). In other words, vocabulary knowledge is highly significant for reading comprehension performance (van den Bosch, Segers \& Verhoeven, 2020). A number of studies (Cain, Oakhill \& Bryant, 2004; Cheng \& Matthews, 2018; Hadley, Dickinson, Hirsh-Pasek, Golinkoff \& Nesbitt, 2016; Masrai, 2019; Noreillie, Desmet \& Peters, 2020; Quinn, Wagner, Petscher \& Lopez, 2015; Vellutino, Tunmer, Jaccard \& Chen, 2007) have demonstrated that a significant association exists between vocabulary knowledge and reading comprehension. For example, vocabulary researchers have primarily stressed on the important role played by vocabulary size or breadth (i.e. how many words one knows) in reading comprehension (i.e. Jeon \& Yamashita, 2014; Laufer, 1992, 1996; Milton, 2013; Na \& Nation, 1985; Nation, 1990, 2001; Read, 2000). Nevertheless, far less about vocabulary depth or different dimensions of the depth of vocabulary knowledge (i.e. vocabulary knowledge that pertains to the quality of words) have been investigated by researchers (Schmitt, 2014). According to Qian (2002), both breadth and depth dimensions deserve equal merit for examining the important role vocabulary knowledge has in reading comprehension. Existing researchers that encompassed depth of vocabulary knowledge put stress on mainly syntagmatic (synonymy and polysemy) and paradigmatic (collocation) relation of vocabulary depth knowledge and their relationship with reading comprehension in English as a Second Language (ESL)/English as a Foreign Language (EFL) contexts (Li and Kirby, 2015; Qian, 1999, 2000, 2002; Read, 1993, 1998; Zhang, 2012).

Moreover, according to Read (2004), that there are three essential associations between the target words and associates; they are analytic relations (that express a vital constituent of the meaning of the target word), syntagmatic relation (collocates), and paradigmatic relation (which is comprised of superordinates and synonyms). Besides, Winston, Chaffin, and Hermann (1987) proposed that analytic relations could be considered as a significant category/kind of semantic relation. According to Schmitt and Meara (1997), word association knowledge plays a significant role in the field of language learning. Thus, analytic (partwhole) relations is reckoned as one important constituent of vocabulary depth knowledge. To the best knowledge of the researchers, employing quantitative investigation, little is known about empirical studies that investigated the correlations and prediction of dissimilar constituents of analytic relations to reading comprehension.

Greidanus and Nienhuis (2001) conducted a study on three types of associations, namely paradigmatic, syntagmatic and analytic (defining characteristics, such as 
those used in dictionary definitions) relations, and they found that for both higher-proficiency learners and lower-proficiency learners, the scores for both paradigmatic association and analytic association were significantly higher than those for the syntagmatic association. Their study included 54 learners of French from two Dutch-speaking universities without considering learners from English as a foreign language (EFL) context. Their study investigated only association among paradigmatic, syntagmatic, and analytic relations, and did not examine any prediction of paradigmatic, syntagmatic or manifold dimensions of analytic relations to academic reading comprehension. Moreover, the study of Horiba (2012) included Chinese and Korean learners who were learning Japanese, and her study did not include any learners from any ESL or EFL context. Her study found that analytic relations accounted for only a little (i.e. $4 \%$ ) variance in text comprehension. Finally, her study did not include different parts of analytic relations and their prediction to reading comprehension. Additionally, the study of Read (1993) included analytic relations in his study, but he tried to justify the validity of the test of the Word Associate Test (analytic relations is one component of the test). He did not conduct an empirical study that related the prediction of analytic relations to reading comprehension. The authors of this research paper have not come across any more study that deals with the prediction of analytic relations to academic reading comprehension. This aspect of a research gap has been delved into the present research project. As previously mentioned, there has been a lack of empirical research that dealt with different dimensions of analytic relations (part-whole relation) and their correlations and prediction to academic reading comprehension. To this end, employing an adapted analytic relations test, this study investigated the correlations and prediction of six dimensions of analytic relations to academic reading comprehension among EFL students of Business and Engineering Schools at the tertiary level in Bangladesh.

\subsection{Theoretical Framework}

\subsubsection{Analytic Relations}

According to Schwartz and Katzir (2012), academics consider another type of lexical hierarchy which is partonomic. Generally, partonomic is known as a partwhole hierarchy (holonymy or meronymy). An example of meronymy is body parts (head-nose). According to Read (2004), meronymy comes under analytic sense relation. The diagram below is given to show the part-whole relationship.

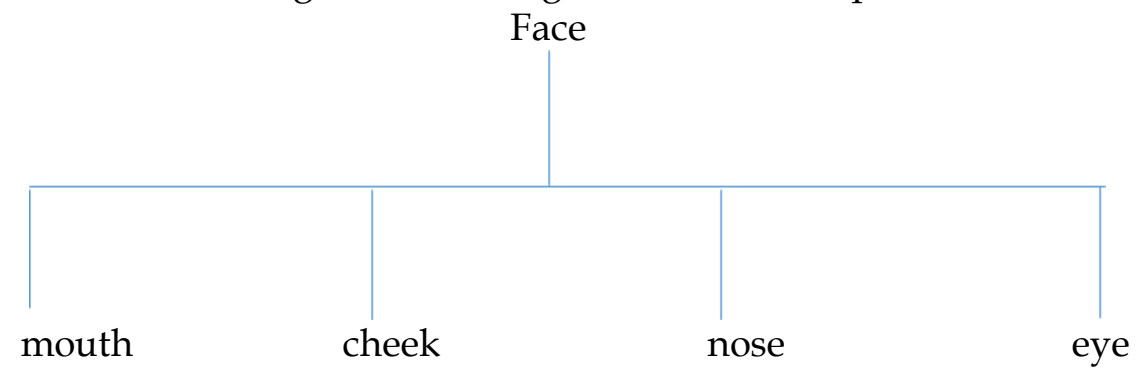

(Source: Finegan, 2008: 191)

It is apparent from the above diagram that the nose is a 'part of the face'. 1.1.2. Parts of Analytic Relations 
Winston, Chaffin, and Hermann (1987, p. 421) in their study provided a taxonomy of analytic relations, and they proposed six types of analytic relations.

The types were

- 'component- integral' (i.e. a relation between components and the objects that they belong; e.g. pedal-bike, handle-cup, punchline-joke, wheels-car, refrigerator-kitchen, chapters-books, Belgium-NATO, Phonology-Linguistics, engine-car),

-member-collection (i.e. a collection is fixed based on spatial proximity or by social connection; e.g. ship-fleet, tree-forest, card-deck, juror-jury),

- portion-mass (i.e. including parts that are identical to one other and to the whole that they consist of; e.g. slice-pie, grain-salt, yard-mile, hunk-clay),

- stuff-object (i.e. a relation that is most often expressed, employing the 'is partly' frame; e.g. steel- car/bike, gin-martini, hydrogen-water),

-feature-activity (i.e. a relation that is pointed out by the use of 'part' to designate the features or phases of activities and processes; e.g. payingshopping, dating-adolescence, bidding-playing bridge, ovulation-menstrual cycle),

- place-area (i.e. the relation between areas and special places and locations within them; e.g. Everglades-Florida, Oasis-desert, baseline-tennis court).

Their work was conducted taking the 'cognates' (cognitive) perspective, not considering the classifications as aspects of vocabulary knowledge and their (dimensions') correlation and prediction to reading skill, not even in any English as a Second Language (ESL) or English as a Foreign Language (EFL) contexts. This aspect of the research gap has been delved into the present research project.

\subsubsection{Theory Relating Vocabulary to Comprehension}

Researchers and teachers are perplexed about determining the exact nature of vocabulary knowledge (Schmitt, 2014) because a lexicon consists of thousands of words, and each comprises various, innumerable links with other words in terms of the lexical network. Furthermore, the nature of vocabulary knowledge is not identified and defined clearly (Li \& Kirby, 2015). As a result, there is a lack of definition, which shows that the definition is 'clearly theory-driven' (Li \& Kirby, 2015, p. 614).

To address the research gap in previous studies and based on the discussion in the literature review, the current study investigates the following research questions:

1. How are member-collection, portion-mass, component-integral, stuff-object, place-area, and feature-activity analytic relation dimensions related to academic reading comprehension?

2. To what extent do member-collection, portion-mass, component-integral, stuff-object, place-area, and feature-activity analytic relation dimensions contribute to predicting the performance of EFL learners' academic reading comprehension? 
3. Which constituent of analytic relations, i.e. component-integral, membercollection, portion-mass, stuff-object, feature-activity, and place-area, is the most contributing predictor of academic reading comprehension?

4. To what level do dissimilar constituents of analytic relations, i.e. membercollection, portion-mass, component-integral, stuff-object, place-area, and feature-activity affect EFL learners' academic reading comprehension?

\section{Methodology}

\subsection{Participants}

The participants of the study were a sample of 155 Bangladeshi EFL students (five sections) in the first year of their graduation from a mid-level private university in Dhaka, Bangladesh. A total of 91 participants from three sections of Business School, namely Bachelor of Business Administration in Finance or other majors $(n=36)$ and Bachelor of Science in Economics $(n=25)$ and Bachelor of Business Administration in Accounting $(n=30)$ was included in the present study. Out of them, 51 were female $(56 \%)$ and 40 were male $(44.0 \%)$, with an average age of around 20.54 (Standard Deviation=1.241, range 18-24). Moreover, a total of 64 students, studying Engineering participated in the current study. Out of them, 20 were female $(31.3 \%)$ and 44 were male $(68.8 \%)$, with an average age of about 20.16 (Standard Deviation=1.027, range 18-23). One section consisted of 31 students who were pursuing studies in Bachelor of Science in Electrical and Electronic Engineering, and the other section comprised of 33 students who were under the Department of Computer Science \& Engineering. All of the students were selected based on their passing Basic English Skill (Credit course 1) course which was approximately at the A2-B1 level on the Common European Framework of Reference. Bengali was the mother tongue of students of both Business and Engineering Schools. The students of the study used English as a foreign language. Participants of the study had at least 12 years of learning English, i.e., all the students who participated in the study had an average of 12 years of exposure to English learning. They had no experience of staying in any native English-speaking country.

\subsection{Measures}

One analytic relations vocabulary measure consisted of six dimensions and one academic reading comprehension test comprised of three multiple-choice passages were employed in the present study.

\subsubsection{Analytic Relations Test}

Analytic relations test for the current study was adapted based on the idea of part-whole relations propagated by Winston et al. (1987), and the test aimed to measure the part-whole relations of words. Analytic relations test of the current study comprised 30 items (refer to Appendix A), and under each item, there were two groups, and each group contained words. Each different column had four words, and out of the eight words, four words were associates to the stimulus words whereas the other four words worked as distractors. An incorrect selection of the answer was given 0; four correct answers of each item constituted 1 point $(0.25 \times 4=1)$; as a result, the maximum achievable score of the analytical relations was $1 \times 30=30$. 
In addition, the test-takers were required to encircle either part or whole meaning of the words in each item. In scoring analytical relations, 0.25 point was given for each appropriate answer, so the highest score for the test was 30. Six types of analytic relations were investigated under the analytic relations test for the current study. The example of the first one, 'component-integral object' relates 'handle-cup' or 'punchline-joke' type of analytic relation; secondly, 'treeforest' or 'card- deck' is an example of 'member-collection' analytic relation. The third category of analytic relation encompasses 'portion-mass', and 'slice-pie' or 'grain-salt' is an example of the 'portion-mass' category of analytic relation. An example like 'gin-martini' or 'steel-bike' is classified under 'stuff-object' analytic relation. The fifth category, 'feature-activity' of analytic relation incorporates examples like 'paying-shopping' or 'dating-adolescence'. The last and the sixth category of analytic relation was 'place-area', and 'oasis-desert' or "EvergladesFlorida' is an example of 'place-area' type of analytic relation.

\subsubsection{Reading Comprehension Test}

Reading comprehension test of the study was a standard multiple-choice academic reading comprehension test, and this reading comprehension test was adopted from Longman Test of English as a Foreign Language (TOEFL) (Philips, 2006, pp. 343-345) and Berita English (2014). Out of several passages, three texts were selected for the current study, and the total number of multiple-choice questions was 20. The maximum possible score for the reading comprehension test was 20 as there was a total of 20 questions (refer to Appendix B). The stipulated total time for each class of the university where the present study was conducted was one hour and 20 minutes (80 minutes). Conducting the two tests, including the five original TOEFL passages would take more time (85 minutes) than the total class time, and the time for filling up the consent form and making the students comprehend the instructions for the two tests would add five minutes. As a result, the researchers shortened the original reading passages into three.

\subsection{Research Design and Data Collection Procedures}

The current study followed a multiple regression analysis of the correlation design under quantitative research. In other words, the quantitative approach was selected, and correlation design was used to describe the potential associations and predictions among the variables. Before administering the two instruments, namely the analytic relations and academic reading comprehension test, a printed 'letter of informed consent' and a 'background questionnaire' were provided to the students. In the letter of informed consent, there was an option (tick $\sqrt{ }$ or $x$ ) where students were asked whether they would participate or not. The participation of the students for the tests measure was voluntary. Purposive sampling in the first place and random sampling as the second step were employed for the present study. One reading comprehension test and an analytic relations test were administered in one session in the students' regular English class. Students were provided 25 minutes to complete the reading comprehension test and another 30 minutes to perform the analytic relations test. 
To find out the level of intercorrelations among six dimensions of the analytic relations and academic reading comprehension, the two-tailed Pearson Correlation (Pearson's r) was selected as the key instrument for analysing the data. To determine the level of prediction of different dimensions of the analytic relations to academic reading comprehension, a standard multiple regression analysis was carried out. In other words, force-entry multiple regression (not stepwise) analysis was applied to find out the significant role played by different dimensions of the analytic relations in explaining the variance in academic reading comprehension. For analysing the data, the researchers employed SPSS version 24 (Statistical Package for Social Studies) as the main statistical program.

\subsection{The Validity of the Instruments of the Study}

Before conducting the main study, the researcher piloted the instruments, namely an analytic relations test and an academic reading comprehension test in order to measure the reliability and validity of the adapted items used for the depth of vocabulary knowledge test for EFL learners. Kuder-Richardson Formula 20 or K-R-20 is used for measuring the reliability of a test which consists of right or incorrect answers, and it is designed to investigate how well a test measures that a researcher intends to measure (Alderson, Clapham \& Wall, 1995). Considering K-R 21 as a method of rational equivalence for examining the internal consistency (Alderson et al. 1995) of the two tests, K-R 21 was employed to calculate their reliability coefficients. The computing of K-R 21 was performed, following the formula which is $\left[n /(n-1) *\left[1-\left(M^{*}(n-M) /\left(n^{*} \operatorname{Var}\right)\right)\right]\right.$ where ' $\mathrm{n}$ ' stands for 'sample size'; 'Var' stands for 'variance for the test', and ' $\mathrm{M}^{\prime}$ stands for 'mean score for the test'.

Table 1 shows the reliability coefficients of the two tests that were conducted to identify the validity and reliability of the adapted or adopted content or construct, (i.e. analytic relations and academic reading comprehension).

Table 1: K-R reliability coefficients of the study

\begin{tabular}{|c|c|}
\hline Test & K-R Reliability Coefficients \\
\hline Analytical Relations & 0.631 \\
\hline Reading Comprehension & 0.63 \\
\hline
\end{tabular}

The $r$ values (reliability coefficients) of the two tests showcased in Table 1 were moderate. Even though K-R 21 employs less information to compute, it always provides a lower reliability index than produced by other methods (Alderson et al. 1995). In general, a score above .50 is considered reasonable. Salvucci, Walter, Conley, Fink, and Saba (1997, p. 115) propose that concerning the extent of reliability scale, the reliability is reckoned low if the value of $r$ is to a lesser degree than 0.50; the reliability is considered as moderate if the value of $r$ is in the middle of 0.50 and 0.80 ; on the other hand, the reliability is considered as high when the value of $r$ is more than 0.80 . K-R 21 most often renders a lower reliability index compared with other methods although K-R 21 uses less 
information to compute (Alderson et al, 1995). In conclusion, it can be said that all the items incorporated in the two instruments under the current study showed an acceptable level of internal consistency while assessing their respective measures. In other words, the $r$ values of the two tests prove that the tests are both reliable and valid.

\subsection{Normality Test}

One of the assumptions of Pearson's $R$ is that the data needs to be normally distributed. The following discussion shows that the data of the present study were normally distributed. Thus, the assumption of Pearson' $R$ allowed the researcher to use it as an analysis method. A normality test can be done in various ways to check out whether a data set possesses normal distribution. One way to test the normality can be done by checking the values of KolmogorovSmirnov and Shapiro-Wilk normality tests. In order to accept a regression model, it is known that a perfect regression model should have a residual which is normally distributed. The null hypothesis apprises that residuals are normally distributed to have a well-fitted regression model. The alternative hypothesis suggests that residuals are not normally distributed. Table 2 shows the values of the normality tests of both Kolmogorov-Smirnov and Shapiro-Wilk.

Table 2: Tests of Normality

\begin{tabular}{|l|c|c|c|c|c|c|c|}
\hline \multirow{2}{*}{} & \multicolumn{4}{|c|}{ Kolmogorov-Smirnova $^{\text {a }}$} & \multicolumn{4}{|c|}{ Shapiro-Wilk } \\
\cline { 2 - 8 } & Statistic & $\mathrm{df}$ & Sig. & Statistic & $\mathrm{df}$ & Sig. \\
\hline $\begin{array}{c}\text { Studentized } \\
\text { Residual }\end{array}$ & .038 & 146 & $.200^{*}$ & .996 & 146 & .942 \\
\hline * This is a lower bound of the true significance. \\
a. Lilliefors Significance Correction \\
\hline
\end{tabular}

As shown in Table 2, the 'sig' or probability value $(p=.200)$ of KolmogorovSmirnov was more than $0.05(p<.05)$, and here the 'sig' value was $20 \%$ which was more than 05 percent; as a result, the null hypothesis could not be rejected rather the null hypothesis would be accepted. This means that the Studentized Residual was normally distributed. On the other hand, after an observation of the 'sig' value $(p=.942)$ of Shapiro-Wilk, it can be found that the 'sig' value was about $94.2 \%$, and the value was more $05 \%(p<.05)$, so the null hypothesis could not be rejected as well; instead, the null hypothesis was accepted. This means that residuals were normally distributed, and that was desirable for the estimated regression model of the study.

\section{Results}

Research question 1 relates 'How are member-collection, portion-mass, component-integral, stuff-object, place-area, and feature-activity analytic relation dimensions related to academic reading comprehension?' To answer the research question 1, a two-tailed Pearson Correlation was conducted, and the results are presented in Table 3. 
Table 3: Correlations among six components of analytic relations with each other and academic reading comprehension

\begin{tabular}{|l|c|c|c|c|c|c|}
\hline & $\begin{array}{l}\text { Component- } \\
\text { Integral }\end{array}$ & $\begin{array}{l}\text { Member- } \\
\text { Collection }\end{array}$ & $\begin{array}{l}\text { Portion } \\
\text {-Mass }\end{array}$ & $\begin{array}{l}\text { Stuff- } \\
\text { Object }\end{array}$ & $\begin{array}{l}\text { Feature- } \\
\text { Activity }\end{array}$ & $\begin{array}{l}\text { Place- } \\
\text { Area }\end{array}$ \\
\hline $\begin{array}{l}\text { Member- } \\
\text { Collection }\end{array}$ & $0.481^{* *}$ & ---- & & & & \\
\hline $\begin{array}{l}\text { Portion- } \\
\text { Mass }\end{array}$ & $0.500^{* *}$ & $0.398^{* *}$ & --- & & & \\
\hline $\begin{array}{l}\text { Stuff- } \\
\text { Object }\end{array}$ & $0.581^{* *}$ & $0.300^{* *}$ & $0.273^{* *}$ & --- & & \\
\hline $\begin{array}{l}\text { Feature- } \\
\text { Activity }\end{array}$ & $0.477^{* *}$ & $0.370^{* *}$ & $0.331^{* *}$ & $0.278^{* *}$ & --- & \\
\hline Place-Area & $0.416^{* *}$ & $0.330^{* *}$ & $0.222^{* *}$ & $0.414^{* *}$ & $0.257^{* *}$ & -- \\
\hline RC & $0.499^{* *}$ & $0.225^{* *}$ & $0.373^{* *}$ & 0.098 & $0.280^{* *}$ & $0.221^{* *}$ \\
\hline
\end{tabular}

${ }^{* *}$ Correlation is significant at the 0.01 level (2-tailed)

As shown in Table 3, inter-correlations among the scores of six independent variables (i.e. dimensions of analytic relations) were all statistically significant. A significant and positive correlation at the 0.01 level $(r=.481 ; p=.001)$ was found between component-integral part of analytic relations and member-collection part of analytic relations. According to Cohen (1988, p. 80), in behavioural sciences, a correlation of $r$ about 0.50 generally indicates a 'large correlation effect size'. This suggests that those students who learned component-integral part of analytic relations also learned the member-collection dimension of analytic relations. Also, a significant and positive correlation at the 0.01 level $(r$ $=.500 ; p=.000$ ) was found between the component-integral part of analytic relations and the portion-mass part of analytic relations. This suggests that those students who learned component-integral part of analytic relations also learned the portion-mass aspect of analytic relations. The same can be observed regarding the correlation between component-integral and stuff-object facet of analytic relations. A significant and positive correlation at the 0.01 level $(r=.581$; $p=.000$ ) existed between component-integral and stuff-object features of analytic relations. This indicates that those students who learned component-integral part of analytic relations also learned the stuff-object feature of analytic relations. Out of the inter-correlations among the six dimensions of analytic relations, the significant correlation between component-integral analytic relations component and stuff-object analytic relations dimension was the highest $(r=.581)$.

Moreover, component-integral analytic relations part correlated in a significant way at the 0.01 level $(r=.477 ; p=.000)$ with feature-activity facet of analytic relations. This suggests that the growth of students' learning of the componentintegral part of analytic relations was positively proportionate to students' learning of the feature-activity dimension of analytic relations. Besides, the component-integral dimension held a significant, positive correlation at the 0.01 level $(r=.416 ; p=.000)$ with the place-area feature of analytic relations. This suggests that the growth of students' learning of component-integral part of analytic relations was positively proportionate to students' learning of place- 
area facet of analytic relations. From the above discussion, in terms of the correlation between component-integral analytic relations and the other five independent variables, it can be inferred that inter-correlations among the scores of member-collection, portion-mass, component-integral, stuff-object, place-area, and feature-activity were all significant statistically.

As shown in Table 3, looking at inter-correlations between member-collection analytic relations part and other dimensions of analytic relations, it was found that inter-correlations among the scores of portion-mass, member-collection, place-area, and feature-activity analytic relations elements were positive and statistically significant. Member-collection analytic relations part correlated $(r$ $=.300 ; p=.000$ ) significantly with stuff-object analytic relations dimension. This shows that the students who learned the member-collection part of analytic relations also learned the stuff-object aspect of analytic relations. Membercollection analytic relations part had positive, significant correlation at the 0.01 level $(r=.398 ; p=.000)$ with portion-mass analytic relations part. This highlights that those students who learned the member-collection part of analytic relations also learned the portion-mass aspect of analytic relations. Besides, membercollection analytic relations dimension bore a significant positive correlation at the 0.01 level $(r=.370 ; p=.000)$ with feature-activity analytic relations part, and this entails that learners who learned member-collection analytic relations also learned feature-activity aspect of analytic relations. Furthermore, a positive, significant correlation at the 0.01 level $(r=.330 ; p=.000)$ was located between member-collection analytic relations part and place-area dimension of analytic relations. This implies that learners who gained knowledge about a membercollection part of analytic relations also learned the place-area dimension of analytic relations.

As presented in Table 3, correlations between portion-mass and stuff-object, and between portion-mass and feature-activity, and between portion-mass and place-area analytic relations dimensions were positive and significant. The positive and significant correlation at the 0.01 level $(r=.273 ; p=.001)$ between portion-mass and stuff-object signifies that students who learned portion-mass aspect of analytic relations also learned equally well the facet of the stuff-object segment of analytic relations. In addition, the significant positive correlation at the level 0.01 of $(r=.331 ; p=.000)$ between portion-mass analytic relation feature and feature-activity facet of analytic relations suggests that students' learning of portion-mass analytic relations aspect had an identical proportion of learning of feature-activity analytic relations component. Also, the significant positive correlation at the level of $0.01(r=.222 ; p=.006)$ between portion-mass and placearea element of analytic relations suggests that learners who gained knowledge about a portion-mass part of analytic relations also learned place-area dimension of analytic relations.

Results presented in Table 3 show that the stuff-object segment of analytic relations held positive and significant correlation with both feature-activity and place-area analytic relations dimensions. The significant positive correlation at the level of $0.01(r=.278 ; p=.000)$ between stuff-object analytic relations aspect 
and feature-activity analytic relations part suggests that those students who learned stuff-object analytic relations also learned feature-activity analytic relations dimension. Furthermore, the significant, positive correlation at the level of $0.01(r=.414 ; p=.000)$ between stuff-object and place-area analytic relations dimension suggests that the growth of students' learning of stuff-object analytic relations aspect was positively proportionate to students' learning of place-area dimension of analytic relations. Finally, as shown in Table 3, positive, significant correlation existed at the level of $0.01(r=.257 ; p=.001)$ between feature-activity and place-area aspect of analytic relations. The results of Table 3 show that inter-corrections among all six variables were positive and significant. In light of the above discussion, the significant, positive correlations among all independent variables have been provided in Figure 1.

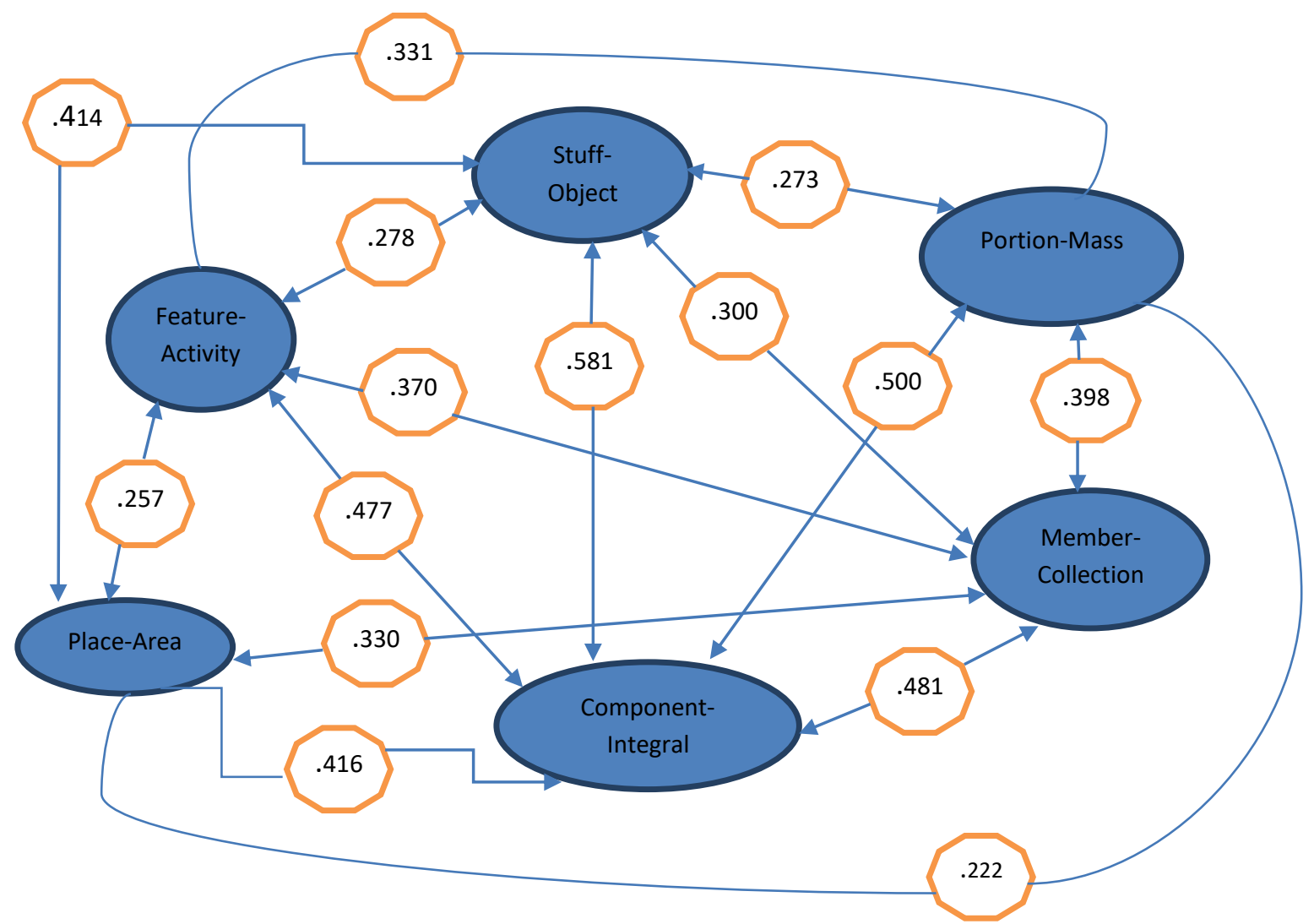

Figure 1: Correlations among the six independent variables

In order to address the other part of research question 1, as presented in Table 3 , the inter-correlations between the scores of all independent variables and academic reading comprehension, except between stuff-object and reading comprehension were found positive, and statistically significant. As shown in Table 3, a statistically significant, positive, and high correlation at the level of $0.01(r=.499 ; p=.000)$ was found between the component-integral part of analytic relations and academic reading comprehension. The correlation between component-integral and academic reading comprehension was the highest compared to associations with other independent variables and 
academic reading comprehension. Moreover, portion-mass analytic relations part bore positive and statistically significant correlation at the level of 0.01 ( $r=$ $.373 ; p=.000$ ) with academic reading comprehension.

Furthermore, the inter-correlations between the scores of the other three independent variables, namely member-collection $(r=.225 ; p=.006)$, featureactivity $(r=.280 ; p=.001)$ and place-area $(r=.221 ; p=.007)$, and dependent variable, academic reading comprehension were positive, and each correlation with reading comprehension was significant at the 0.05 level $(p<.01)$. This suggests that those students who learned component-integral analytical relations part performed better in academic reading comprehension compared to other dimensions of analytic relations. In addition, those Business and Engineering EFL learners who learned portion-mass, member-collection, placearea, and feature-activity analytic relations aspects performed well in academic reading comprehension. In other words, all five constituents of analytic relations, namely member-collection, portion-mass, component-integral, placearea, and feature-activity analytic relations aspects helped learners perform better in academic reading success. The inter-correlations between five independent variables and academic reading comprehension are presented in Figure 2.

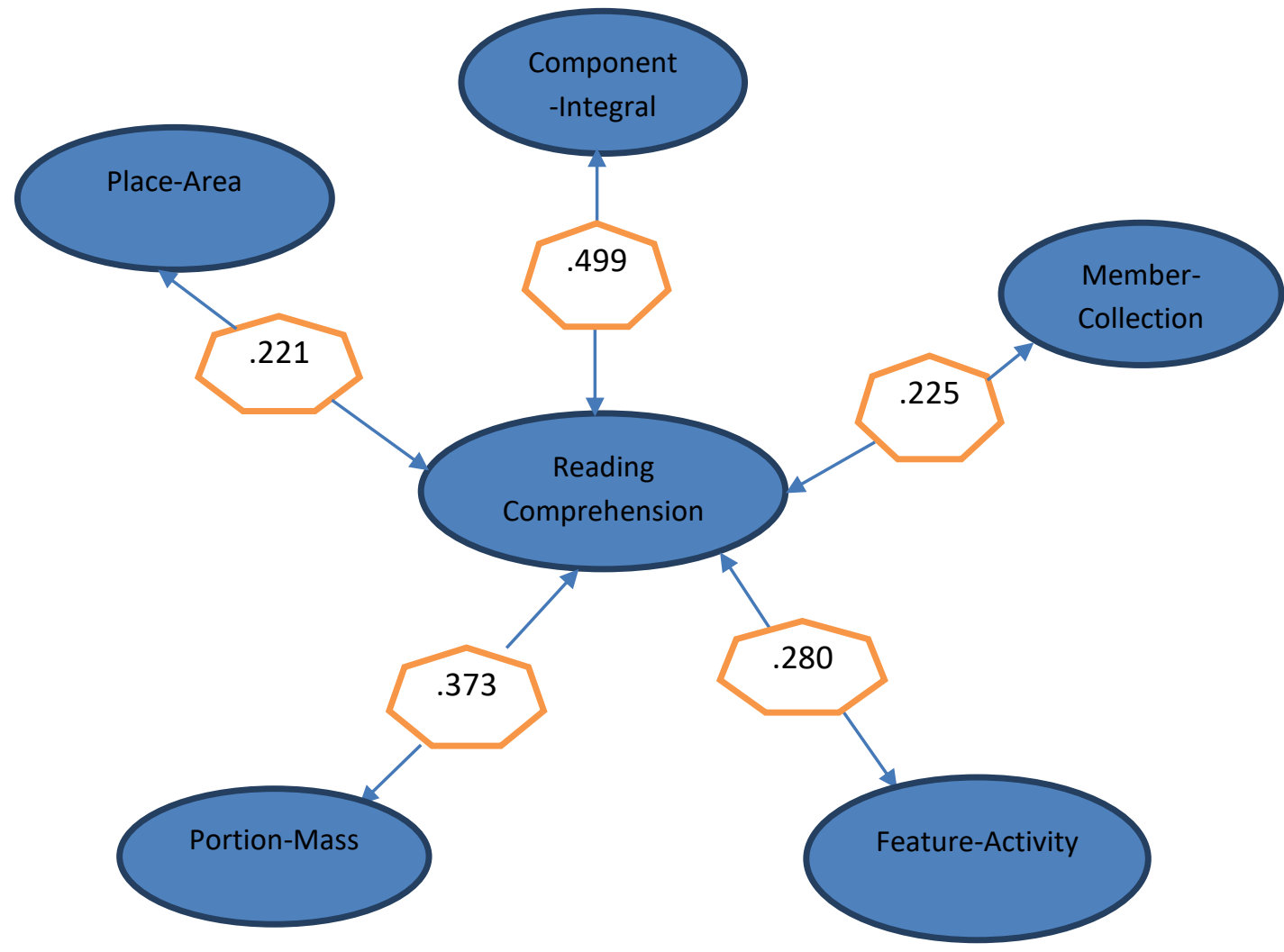

Figure 2: Correlations among five independent variables and reading comprehension 
The second research question alludes to: 'To what extent do member-collection, portion-mass, component-integral, stuff-object, place-area, and feature-activity analytic relation dimensions contribute to predicting the performance of EFL learners' academic reading comprehension?' and the third research question relates: 'Which constituent of analytic relations, i.e. component-integral, member-collection, portion-mass, stuff-object, feature-activity, and place-area, is the most contributing predictor of academic reading comprehension?'

Research questions two and three were developed to determine the most significant, unique predictor of academic reading comprehension and to address the extent of prediction of member-collection, portion-mass, component-integral, stuff-object, place-area, and feature-activity analytic relation parts to academic reading comprehension. Tables 4 and 5 show prediction value, ANOVA, and coefficient values of all six dimensions of the analytic relations on academic reading comprehension in terms of the scores of students from both the Business school and Engineering school.

Table 4: Prediction and ANOVA Values of Six Components of Analytic Relations of all Students' Score

\begin{tabular}{|c|c|c|c|c|c|c|c|c|c|}
\hline & & & \multirow{6}{|c|}{ Std. } & \multicolumn{6}{|c|}{ ANOVA } \\
\cline { 5 - 11 } & \multirow{2}{*}{$\boldsymbol{R}^{2}$} & $\begin{array}{c}\text { Adjusted } \\
\boldsymbol{R}^{2}\end{array}$ & $\begin{array}{c}\text { Error of } \\
\text { the } \\
\text { Estimate }\end{array}$ & $\begin{array}{c}\text { Sum of } \\
\text { Squares }\end{array}$ & $d f$ & $\begin{array}{c}\text { Mean } \\
\text { Square }\end{array}$ & $F$ & Sig. \\
\hline .576 & .332 & .303 & 2.758 & 526.185 & 6 & 87.698 & 11.526 & .000 \\
\hline
\end{tabular}

A. Dependent Variable: Reading Comprehension, B. Predictors: (Constant), MemberCollection Analytic Relation, Portion-Mass Analytic Relation, Stuff-Object Analytic Relation, Feature-Activity Analytic Relation, and Place-Area Analytic Relation

Table 5: Coefficients of All Six Variables of Analytic Relations of Students of Business and Engineering Schools

\begin{tabular}{|c|c|c|c|c|c|}
\hline \multirow{2}{*}{$I^{a}$} & \multicolumn{2}{|c|}{ Correlations } & \multirow{2}{*}{ Sig. } & \multicolumn{2}{|c|}{ Collinearity Statistics } \\
\hline & Partial & Part & & Tolerance & VIF \\
\hline $\begin{array}{l}\text { Component- } \\
\text { integral }\end{array}$ & .423 & .382 & .000 & .446 & 2.244 \\
\hline Member-Collection & -.068 & -.055 & .425 & .700 & 1.429 \\
\hline Portion-Mass & .168 & .139 & .047 & .711 & 1.406 \\
\hline Stuff-Object & --.284 & -.242 & .001 & .626 & 1.597 \\
\hline Feature-Activity & .043 & .035 & .611 & .739 & 1.353 \\
\hline Place-Area & .090 & .074 & .290 & .760 & 1.315 \\
\hline
\end{tabular}

Dependent Variable: Reading Comprehension; aIndependent Variable

For checking the validity of the multiple regression model, the value of ANOVA in Table 4 can be looked into. Since the ' $\mathrm{f}$ ' statistics were found to be significant at the 0.001 level $(R 2=.576), F(6,139)=11.526, p=.000$, the run regression model 
was found to be well-fitted for the data. Table 5 shows the prediction value, coefficient values of all six independent variables on the dependent variable and the significance value of the model's fitness in terms of the scores of students from both the Business school and Engineering school.

As shown in Table 4, the value $R$, multiple correlation coefficient, of .576 shows an acceptable level of prediction for students of Business and Engineering Schools. As Table 5 shows, component-integral part of analytic relations uniquely explained about $(.382) 2=14.5924 \%$ of the variance in the dependent variable, academic reading comprehension; member-collection alone explained $(-.055) 2=.3025 \%$ of the variance in academic reading comprehension; portionmass alone explained (.139) $2=1.9321 \%$ of the variance in academic reading comprehension; stuff-object alone explained $(-.242) 2=5.8564 \%$ of the variance in academic reading comprehension; feature-activity alone explained $(.035) 2=.1225 \%$ of the variance in academic reading comprehension, and placearea alone explained about $(.074) 2=.5476 \%$ of the variance in academic reading comprehension. The highest unique variance $(14.5924 \%)$ in academic reading comprehension was explained by component-integral part of analytic relations, and followed by stuff-object (5.8564), portion-mass $(1.9321 \%)$, place-area $(0.5476 \%)$, member-collection $(0.3025)$, and feature-activity $(0.1225 \%)$ dimension of analytic relations respectively.

Furthermore, component-integral had (.423) $2=17.8929 \%$ shared variance with the five other independent variables in academic reading comprehension. On the other hand, the stuff-object facet of analytic relation had $(-.284) 2=8.0656 \%$ shared variance with five other independent variables in academic reading comprehension. The portion-mass dimension of analytic relations had (.168)2= $2.8224 \%$ shared variance with five other independent variables in academic reading skill, and place-area facet of analytic relations had $(.090) 2=.81 \%$ shared variance with the five other independent variables in academic reading skill. Apart from them, the member-collection component of analytic relations had ($.068) 2=.4624 \%$ shared variance with the five other independent variables in academic reading skill, and the feature-activity aspect of analytic relations had $(.043)=.1849 \%$ shared variance with the five other independent variables in academic reading skill.

The present research dealt with research question four, which is: 'To what level do different constituents of analytic relations, i.e. member-collection, portionmass, component-integral, stuff-object, place-area, and feature-activity affect EFL learners' academic reading comprehension?' Table 5 puts forward the effects of six components of the analytic relations on academic reading comprehension. 
Table 6: Coefficients of Six Variables of Analytic Relations of Students' Scores of Business and Engineering

\begin{tabular}{|l|c|c|c|}
\hline \multirow{2}{*}{ IV $^{1}$} & \multicolumn{1}{|c|}{ Standardized Coefficients } & \multirow{2}{*}{ Sig } \\
\cline { 2 - 3 } & \multicolumn{1}{|c|}{$\boldsymbol{t}$} & \\
\hline Component-Integral & .572 & 5.505 & .000 \\
\hline Member-Collection & -.066 & -0.801 & .425 \\
\hline Portion-Mass & .165 & 2.004 & .047 \\
\hline Stuff-Object & -.305 & -3.486 & .001 \\
\hline Feature-Activity & .041 & .0510 & .611 \\
\hline Place-Area & .084 & 1.061 & .290 \\
\hline
\end{tabular}

a. Dependent Variable: Reading Comprehension; ${ }^{1}$ Independent Variable

As presented in Table 6, the largest Beta value of the component-integral analytic relations $(\beta=.572 ; t=5.505, p=.000$ (very significant) $(\mathrm{p}<.01))$ shows that component-integral part of the analytic relations had the largest effect on the outcome variable, academic reading comprehension compared to the variance was explained by the other five variables jointly. The Beta values of other independent variables, namely portion-mass and stuff-object analytic relations indicate that portion-mass analytic relation $(\beta=.165, t=2.004, p=.047$ (significant; $p<.05$ ) and stuff-object $(\beta=-0.305 ; t=-3.486, p=.001$ (significant; $p$ $<.01)$ analytic relation facets made larger effect on explaining outcome variable, reading comprehension than place-area $(\beta=.084, t=1.061, p=.290$ (not significant), member-collection $(\beta=-0.066, t=-0.801, p=.425$ (not significant)), and feature-activity $(\beta=.041, t=1.061, p=.290$ (not significant) analytic relation part.

From the discussion of Beta values of all the six dimensions of analytic relations, it can be inferred that component-integral, stuff-object, and portion-mass analytic relation dimensions had a significant (statistically) effect on academic reading comprehension. Moreover, the other three analytic relations dimensions (i.e. member-collection, feature-activity, and place-area) had an effect on the outcome variable, but they did not have a statistically significant effect on explaining the outcome variable (i.e. academic reading comprehension).

Based on the above discussion, it can be implied that (i) regarding the scores of students of the Business school as well as the Engineering school, the relationship between component-integral analytic relations part and academic reading comprehension was the highest and was found to be both positive and significant; (ii) Students who knew component-integral, portion-mass, membercollection, place-area, and feature-activity analytic relations dimensions performed better in the academic reading comprehension than stuff-object part of analytic relations, (iii) For Business and Engineering school students, component-integral part of analytic relations had the highest unique (significant) 
variance in explaining the outcome variable, 'reading comprehension' when the variance was explained by the other five variables jointly.

\section{Discussion}

Concerning the scores of learners of Business and Engineering schools, as presented in Table 3, the correlation between component-integral analytic relations part had the highest, positive and significant correlation with the stuffobject analytic relations part $(r=.581, p<.01)$. Moreover, this suggests that the two aspects are interconnected, and the development of component-integral analytic relations part contributes to the growth of their stuff-object analytic relations part of the vocabulary knowledge or vice versa. An identical positive and significant correlation $(r=.500, p<.01)$ was found between portion-mass and component-integral analytic relations part of the vocabulary knowledge. In the light of the above discussion, it appears that teachers should incorporate, particularly component-integral, portion-mass, feature-activity, place-area, and member-collection analytic (part-whole) relations aspects in their vocabulary teaching materials to help students build up knowledge of the deeper meaning of the vocabulary knowledge, which would lead them to have greater success in academic reading comprehension.

As presented in Table 3, except one independent variable (i.e. stuff-object analytic relations aspect), the rest of other five independent variables, namely component-integral, portion-mass, member-collection, place-area, and featureactivity analytic relation facets were positively, either strongly or moderately correlated with the dependent variable, academic reading comprehension. This result was expected because all the six dimensions of analytic relations investigated in the study showed that they formed a cohort under the same construct, i.e., part-whole relation of lexical knowledge. The obtained result of close, positive and significant inter-correlations among the independent variables and dependent variable proved the point that the investigated six dimensions of analytic relations components needed to be considered substantially as indispensable parts of analytic relations.

As presented in Table 5, statistically significant way, three independent variables, i.e. component-integral, stuff-object, and portion-mass analytic relation dimensions were found to have a more unique contribution in explaining the dependent variable, academic reading comprehension, as well as they, had a larger effect significantly (statistically) on explaining the outcome variable, academic reading comprehension than the other independent variables. This result augured well for the run regression model since at least three of the independent variables statistically significant way contributed to the prediction to the dependent variable, academic reading comprehension.

Even though the reading comprehension tasks in the current study were designed, particularly for basic English comprehension in academic settings, it can be restated that for university-level EFL speakers, component-integral, portion-mass, member-collection, place-area, and feature-activity analytic relations aspects of vocabulary depth knowledge are not only closely, 
significantly and positively related with one another but also with the performance on reading comprehension tasks. We can thus infer that vocabulary, particularly analytic relations of vocabulary knowledge is a vital factor in reading success, and different analytic relations dimensions of vocabulary knowledge as predictor variables prove to be useful to academic reading comprehension.

By evaluating the knowledge, particularly, of component-integral, portion-mass, member-collection, stuff-object, feature-activity, and place-area analytic relations parts in place of target words' merely one meaning, analytic relations draws on in-depth nuances of vocabulary knowledge. As a result, a productive positive influence on teaching and learning new vocabulary can be achieved.

\section{Conclusion}

Many language teachers recognize that vocabulary depth knowledge plays a crucial role in learners' academic success (Choi \& Zhang, 2018; Nakata, Tada, Mclean \& Kim, 2020; Nation, 1983; Schmitt, 2008; Zhang, Lin, Zhang \& Choi, 2017), yet it is still ignored in teaching English in an EFL context. However, in Bangladesh English teachers have a propensity to seemingly irrationally adopt the subscribed curriculum and/or prescribed texts books from western countries. This is a result of a variety of local, national, and global EFL factors. Nonetheless, the context of teaching English as L1 (native language) in western countries is different from the oriental perspective, and the current study corroborated significant different analytic relations dimensions in academic reading success by providing empirical evidence between different dimensions of analytic relations and academic reading comprehension in EFL context.

Analytic relations parts of the present study included component-integral, member-collection, portion-mass, stuff-object, feature-activity, place-area aspects. The results of the study would help teachers to come to know how much vocabulary knowledge in EFL is adequate, and the role vocabulary knowledge would play in EFL reading comprehension of academic texts. Also, English language teachers could be able to make students conscious of the importance of the analytic relations aspect of the knowledge of vocabulary. Thus, awareness amidst learners would successfully help them learn and develop other English language skills as well.

A positive and significant association between analytic relations parts of vocabulary knowledge and academic reading comprehension was found which determined that learners with a higher level of analytic relations showed a propensity to have better academic success. In other words, the above analytic relations aspects that are related to each other are recommended to be highlighted and included in teaching and learning vocabulary since they have a stronger association with reading comprehension.

To the researchers' best knowledge, little is known about studies that included different dimensions of analytical relations jointly and their correlation and prediction to academic reading comprehension, and conducting the present 
research with comprising different dimensions of analytical relations to figure out their association and prediction to academic reading comprehension under quantitative research investigation has added to the body of lexical knowledge.

\subsection{Pedagogical Implications}

Language teachers and practitioners would be able to make use of the results from the correlation and prediction of different types of analytic relations to reading comprehension to gain a better understanding of the significant associations and prediction between the component-integral type of analytic relations and other constituents of analytic relations and reading comprehension that the findings of the current study have shown, which can, in turn, endorse their pedagogical decisions.

When language instructors would support learners in paying attention to the most significant components of analytic relations, namely component-integral and other types of analytic relations, the reading comprehension content will be easier to handle and the amount of work less challenging. This fosters an avenue for learning and teaching to become more effective. Since analytic relations constitutes a significant part of the depth of vocabulary knowledge, the findings of the present study might suggest that EFL learners would be benefitted more in their EFL reading when they are equipped with the deeper knowledge of words, namely component-integral category of analytic relations and other categories of analytic relations.

Vocabulary instructors in general have put greater stress on different ways that can maximize learners' vocabulary size. In the process of doing so, the learners are offered with a long list of vocabulary items to be remembered, and the list of vocabulary items often comprises only plain dictionary meanings. This practice is fallacious since imparting only a restricted definition of a word might hinder students from developing an in-depth knowledge of the words, and this process, in turn, might impede learners' reading performance. Therefore, in their vocabulary instruction, vocabulary instructors should include words that show that learners possess an in-depth understanding of words, encompassing semantic relations, particularly analytic relations which represent vocabulary depth knowledge.

\subsection{Limitations}

To conclude, the current study added to the understanding of association and prediction between different dimensions of analytic relations and academic reading comprehension, but limitation remains. Participants included in the study were from the same university, so more learners from different levels of educational sectors would make this study more comprehensive. Moreover, any impact of the native language (i.e. Bengali) or background knowledge of the learners on the test results was not explored. Concerning participants' study of programmes or major subjects, the study has limited the scope for generalisations of the research findings. 


\section{References}

Alderson, J. C., Clapham, C., \& Wall, D. (1995). Language test construction and evaluation. New York, USA: Cambridge University Press.

Berita-English. (2014, January). Soal TOEFL reading dan kunci jawaban pre-test Longman [Blog post]. Retrieved from http://beritaenglish.blogspot.com/2014/01/soal-toefl-reading-dan-kunci-jawabanpre-testlongman.html?cv=1\&showComment $=1452527635617$

Cain, K., Oakhill, J., \& Bryant, P. (2004). Children's reading comprehension ability: Concurrent prediction by working memory, verbal ability, and component skills. Journal of Educational Psychology, 96(1), 31-42. https:// psycnet.apa.org/record/2004-11358-003

Cheng, J., \& Matthews, J. (2018). The relationship between three measures of L2 vocabulary knowledge and L2 listening and reading. Language Testing, 35(1), 325. https://doi.org/10.1177/0265532216676851

Choi, H. Y. (2013). Effects of depth and breadth of vocabulary knowledge on English reading comprehension among Korean High school students. Language Research, 49(2), 419-452.

Choi, Y., \& Zhang, D. (2018). The relative role of vocabulary and grammatical knowledge in L2 reading comprehension: A systematic review of literature. International Review of Applied Linguistics in Language Teaching. https://doi.org/10.1515/iral-2017-0033.

Cohen, J. (1988). Statistical power analysis for the behavioral sciences (2nd ed.). Hillsdale, NJ, USA: Lawrence Earlbaum Associates.

Finegan, E. (2008). Language: Its structure and use. Boston, USA: Thomson Wadsworth.

Greidanus, T., \& Nienhuis, L. (2001). Testing the quality of word knowledge in a second language by means of word associations: Types of distractors and types of associations. The Modern Language Journal, 85(4), 567-577. https:// doi.org/10.1111/0026-7902.00126

Hadley, E. B., Dickinson, D. K., Hirsh-Pasek, K., Golinkoff, R. M., \& Nesbitt, K. T. (2016). Examining the acquisition of vocabulary knowledge depth among preschool students. Reading Research Quarterly, 51(2), 181-198. https://doi.org/10.1002/rrq.130

Hasan, M. K., \& Shabdin, A. A. (2016). Conceptualization of depth of vocabulary knowledge with academic reading comprehension. PASSA, 51, 235-268.

Horiba, Y. (2012). Word knowledge and its relation to text comprehension: A comparative study of Chinese- and Korean-speaking L2 learners and L1 speakers of Japanese. The Modern Language Journal, 96(1), 108-121. https://doi.org/10.1111/j.1540-4781.2012.01280.x

Jeon, E. H., \& Yamashita, J. (2014). L2 reading comprehension and its correlate: A meta-analysis. Language Learning, 64(1), 160-212. https://doi.org/10.1111/lang.12034

Kang, Y., Kang, H. S., \& Park, J. (2012). Is it vocabulary breadth or depth that better predict Korean EFL learners' reading comprehension? English Teaching, 67(4), $149-171$.

Kezhen, L. I. (2015). A study of vocabulary knowledge and reading comprehension on EFL Chinese learners. Studies in Literature and Language, 10(1), 33-40.

Laufer, B. (1992). How much lexis is necessary for reading comprehension? In P. J. L. Arnaud \& H. Béjoint (Eds.), Vocabulary and applied linguistics (pp. 126-132). London: MacMillian.

Laufer, B. (1996). The lexical threshold of second language reading comprehension: What it is and how it relates to L1 reading ability. In K. Sajavaara \& C. Fairweather 
(Eds.), Approaches to second language acquisition (pp. 55-62). Jyväskylä: University of Jyväskylä.

Li, M., \& Kirby, J. R. (2015). The effects of vocabulary breadth and depth on English Reading. Applied $\quad$ Linguistics, 36(5), 611-634. https://doi.org/10.1093/applin/amu007

Masrai, A. (2019). Vocabulary and reading comprehension revisited: Evidence for high-, mid-, and low-frequency vocabulary knowledge. Sage Open, 9(2), 1-13. https://doi.org/10.1177/2158244019845182

Meara, P. (1980). Vocabulary acquisition: A neglected aspect of language learning. Language Teaching, 13, 221-246.

Milton, J. (2013). Measuring the contribution of vocabulary knowledge to proficiency in the four skills. In C. Bardel, C. Lindqvist \& B. Laufer (Eds.), L2 Vocabulary acquisition, knowledge and use: New perspectives on assessment and corpus analysis (pp. 57-78). Euro SLA. Retrieved on 23 March, 2017 from http://www.eurosla.org/monographs/EM02/Milton.pdf

$\mathrm{Na}$, L., \& Nation, I. S. P. (1985). Factors affecting guessing vocabulary in context. RELC Journal, 16(1), 33-42. https://doi.org/10.1177/003368828501600103

Nakata, T., Tada, S., Mclean, S., \& Kim, Y. A. (2020). Effects of distributed retrieval practice over a semester: Cumulative tests as a way to facilitate second language vocabulary learning. TESOL Quarterly. https://doi.org/10.1002/tesq.596

Nation, P. (1983). Testing and teaching vocabulary. Guidelines, 5, 12-25.

Nation, I. S. P. (1990). Teaching and learning vocabulary. New York: Newbury House.

Nation, I. S. P. (2001). Learning vocabulary in another language. Cambridge, UK: Cambridge University Press.

Noreillie, A. S., Desmet, P., \& Peters, E. (2020). Factors predicting low-intermediate French learners' vocabulary use in speaking tasks. Canadian Modern Language Review-Revue Canadienne Des Langues Vivantes. Retrieved from https:/ / lirias.kuleuven.be/3055545?limo $=0$

Philips, D. (2006). Longman complete course for TOEFL test. New York: Longman Group/A Pearson Education Company.

Qian, D. D. (1998). Depth of Vocabulary Knowledge: Assessing its role in Adults' Reading Comprehension in English as a second language (Doctoral dissertation, University of Toronto, Canada). Retrieved from https://www.collectionscanada.gc.ca/obj/s4/f2/dsk2/ftp02/NQ33914.pdf

Qian, D. D. (1999). Assessing the roles of depth and breadth of vocabulary knowledge in reading comprehension. Canadian Modern Language Review, 56(2), 282-307. https:// doi.org/10.3138/cmlr.56.2.282

Qian, D. D. (2000). Validating the role of depth of vocabulary knowledge in assessing reading for basic comprehension in TOEFL 2000. Research Report. Princeton, NJ: Educational Testing Service.

Qian, D. D. (2002). Investigating the relationship between vocabulary knowledge and academic reading comprehension: An assessment perspective. Language Learning, 52(3), 513-536. https:// doi.org/10.1111/1467-9922.00193

Quinn, J. M., Wagner, R. K., Petscher, Y., \& Lopez, D. (2015). Developmental relations between vocabulary knowledge and reading comprehension: A latent change score modeling study. Child Development, 86(1), 159-175. https://doi.org/10.1111/cdev.12292

Read, J. (1993). The development of a new measure of L2 vocabulary knowledge. Language Testing, 10(3), 355-371. https://doi.org/10.1177/026553229301000308 
Read, J. (1998). Validating a test to measure depth of vocabulary knowledge. In Kunnan, A (Ed.), Validation in language assessment (pp. 41-60). Mahwah, NJ: Lawrence Erlbaum.

Read, J. (2000). Assessing vocabulary. Cambridge, UK: Cambridge University Press.

Read, J. (2004). Plumbing the depths: How should the construct of vocabulary knowledge be defined? In P.Bogaards \& B. Laufer (Eds.), Vocabulary in a second language: Selection, acquisition and testing (pp. 209-227). Amsterdam: John Benjamins.

Salvucci, S., Walter, E., Conley, V., Fink, S., \& Saba, M. (1997). Measurement error studies at the National Center for Education Statistics (NCES). Washington D. C.: U. S. Department of Education

Schmitt, N. (2008). Review article: Instructed second language vocabulary learning. Language Teaching Research, 12(3), 329-363. https://doi.org/10.1177/1362168808089921

Schmitt, N. (2010). Researching vocabulary: A vocabulary research manual. Basingtoke: Palgrave Macmillan.

Schmitt, N. (2014). Size and depth of vocabulary knowledge: What the research shows. Language Learning, 64(4), 913-951. https://doi.org/10.1111/lang.12077

Schmitt, N., \& Meara, P. (1997). Researching vocabulary through a word knowledge framework: Word association and verbal suffixes. Studies in Second Language Acquisition, 19(1), 17-36. https://doi.org/10.1017/S0272263197001022

Schwartz, M., \& Katzir, T. (2012). Depth of lexical knowledge among bilingual children: The impact of schooling. Reading and Writing, 25(8), 1947-1971. https:// doi.org/10.1007/s11145-011-9308-9

van den Bosch, L. J., Segers, E., \& Verhoeven, L. (2020). First and second language vocabulary affect early second language reading comprehension development. Journal of Research in Reading, 1-19. https:/ / doi.org/10.1111/1467-9817.12304

Vellutino, F. R., Tunmer, W. E., Jaccard, J. J., \& Chen, R. (2007). Components of reading ability: Multivariate evidence for a convergent skills model of reading development. Scientific Studies of Reading, 11(1), 3-32. https://www.tandfonline.com/doi/abs/10.1080/10888430709336632

Weixia, W. (2014). Assessing the roles of breadth and depth of vocabulary knowledge in Chinese EFL learners' listening comprehension. Chinese Journal of Applied Linguistics, 37(3), 358-372. https:// doi.org/10.1515/cjal-2014-0022

Winston, M. E., Chaffin, R., \& Herrmann, D. (1987). A taxonomy of part-whole relations. Cognitive Science, 11(4), 417-444. https://doi.org/10.1207/s15516709cog1104_2

Zhang, D. (2012). Vocabulary and grammar knowledge in L2 reading comprehension: A structural equation modelling study. Applied Linguistics, 21, 117-126.

Zhang, Y., Lin, C. H., Zhang, D., \& Choi, Y. (2017). Motivation, strategy, and English as a foreign language vocabulary learning: A structural equation modelling study. British Journal of Educational Psychology, 87, 57-74. https://doi.org/10.1111/bjep.12135

Zhang, D., \& Yang, X. (2016). Chinese L2 learners' depth of vocabulary knowledge and its role in reading comprehension. Foreign Language Annals, 49(4), 699-715. https://doi.org/10.1111/flan.12225 


\section{Appendix 1}

\section{Analytic Relations Test}

Directions: In this test, there are 30 items. Each item looks like this: Car

\begin{tabular}{|l|l|}
\hline (A) wheels $(B)$ mirrors $(C)$ mud $(D)$ engine & $(\mathrm{E})$ solid $(\mathrm{F})$ temperature $(\mathrm{G})$ brakes $(\mathrm{H})$ dance \\
\hline
\end{tabular}

\section{Please Note:}

Some of the words here in the left box show meaning parts of a car.

Some of the words in the right box denote meaning parts of a car.

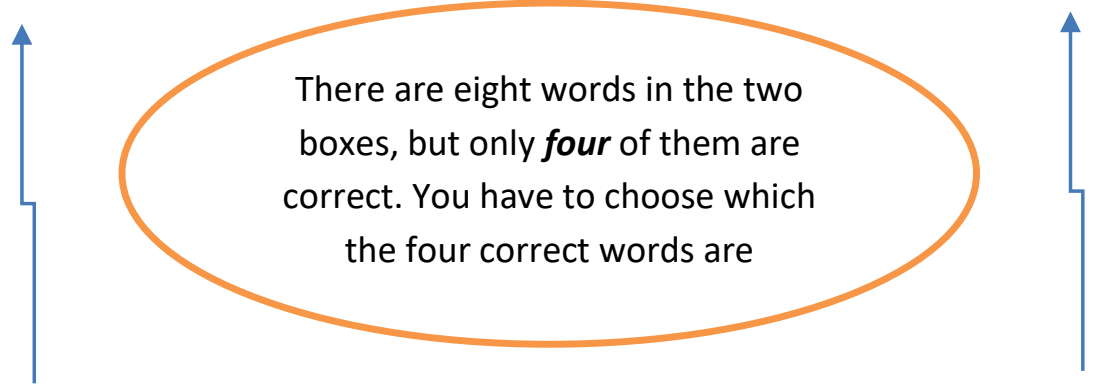

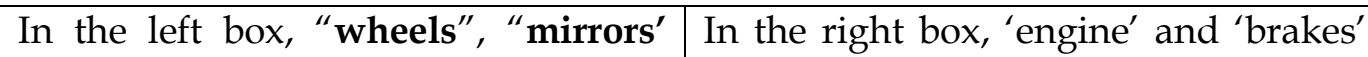
are the meanings of parts of a car. share the meaning of parts of a car.

On your answer sheet, you should mark the answers by encircling the corresponding letters by a pen like this:

(C)

Note: In this example, there are three correct answers on the left and one on the right, but in some other items, there will be either one on the left and three on the right, or two on the left and two on the right.

Read the following and encircle the four correct words:

1. Head

\begin{tabular}{|c|c|}
\hline (A) beautiful (B) department (C) game (D) body & (E) intelligence $(\mathrm{F})$ coin $(\mathrm{G})$ noise $(\mathrm{H})$ school \\
\hline \multicolumn{2}{|l|}{ 2. Pistons } \\
\hline (A) complete (B) car (C) helicopter (D) wheel & $(\mathrm{E})$ vehicle $(\mathrm{F})$ circle $(\mathrm{G})$ name $(\mathrm{H})$ party \\
\hline \multicolumn{2}{|l|}{ 3. Petal } \\
\hline (A) home (B) national (C) flower (D) smooth & $(\mathrm{E})$ animal $(\mathrm{F})$ plant $(\mathrm{G})$ tree $(\mathrm{H})$ bouquet \\
\hline \multicolumn{2}{|l|}{ 4. Bicycle } \\
\hline (A) bell (B) wheels (C) crooked (D) punctual & $(\mathrm{E})$ time $(\mathrm{F})$ pedal $(\mathrm{G})$ beginning $(\mathrm{H})$ seat \\
\hline \multicolumn{2}{|l|}{ 5. Pedal } \\
\hline (A) tandem (B) helpful (C) bicycle (D) rickshaw & $(\mathrm{E})$ error $(\mathrm{F})$ event $(\mathrm{G})$ boat $(\mathrm{H})$ estimate \\
\hline
\end{tabular}




\section{Tea Cup}

\begin{tabular}{|l|l} 
(A) ceramic $(B)$ handle $(C)$ compact $(D)$ thick & (E) saucer $(F)$ view $(G)$ foot tip $(H)$ material
\end{tabular} 7. Joke

\begin{tabular}{|lll|ll|l|}
\hline $\begin{array}{l}\text { (A) punchline } \\
\text { bothersome }\end{array}$ & (B) irritating & (C) laughter & (D) & $\begin{array}{l}\text { (E) favour (F) entertainment (G) weeds } \\
\text { comedy show }\end{array}$ \\
\hline
\end{tabular}

\section{Kitchen}

\begin{tabular}{l|l} 
(A) changed $(B)$ burner $(C)$ important $(D)$ separate & $(E)$ stove $(F)$ sink $(G)$ ideas $(H)$ oven
\end{tabular} 9. Books

\begin{tabular}{|c|c|}
\hline 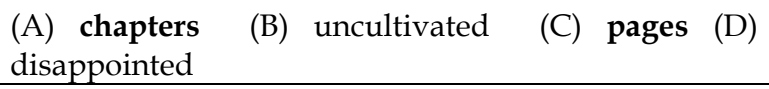 & (E) paper $(\mathrm{F})$ mob $(\mathrm{G})$ index $(\mathrm{H})$ berries \\
\hline \multicolumn{2}{|l|}{ 10. Linguistics } \\
\hline $\begin{array}{l}\text { (A) phonology (B) inexpressible }(\mathrm{C}) \text { language (D) } \\
\text { syntax }\end{array}$ & $\begin{array}{l}\text { (E) discontented }(\mathrm{F}) \text { phonetics }(\mathrm{G}) \text { amount }(\mathrm{H}) \\
\text { need }\end{array}$ \\
\hline
\end{tabular}
11. Tree

\begin{tabular}{|c|c|}
\hline$(\mathrm{A})$ clear $(\mathrm{B})$ leaves $(\mathrm{C})$ important $(\mathrm{D})$ rough & $(\mathrm{E}) \operatorname{wood}(\mathrm{F})$ trunk $(\mathrm{G})$ time $(\mathrm{H})$ branches \\
\hline \multicolumn{2}{|l|}{ 12. Disease } \\
\hline (A) symptom (B) quiet (C) pain (D) tired & (E) fever $(\mathrm{F})$ day $(\mathrm{G})$ infection $(\mathrm{H})$ person \\
\hline
\end{tabular}

\section{Play}

\begin{tabular}{|c|c|}
\hline (A) another (B) chorus (C) actor (D) raw & (E) plots $(\mathrm{F})$ dialogue $(\mathrm{G})$ element $(\mathrm{H})$ water \\
\hline \multicolumn{2}{|l|}{ 14. Fleet } \\
\hline (A) ship (B) famous (C) warship (D) shinning & (E) cruisers $(F)$ hand $(G)$ squadrons $(H)$ taste \\
\hline
\end{tabular}

\section{Forest}

\begin{tabular}{|l|l}
\hline (A) empty (B) trees (C) shrubs (D) useful & (E) vines (F) feet $(G)$ birds $(H)$ tool
\end{tabular}

16. Pie

\begin{tabular}{|c|c|}
\hline (A) slice (B) often (C) lump (D) chunk & $(\mathrm{E})$ angle $(\mathrm{F})$ a piece $(\mathrm{G})$ illness $(\mathrm{H})$ stones \\
\hline \multicolumn{2}{|l|}{ 17. Mile } \\
\hline (A) yard (B) fundamental (C) unit (D) measure & $(\mathrm{E})$ issues $(\mathrm{F})$ quantity $(\mathrm{G})$ wealth $(\mathrm{H})$ dur \\
\hline
\end{tabular}

\section{Motorbike}

\begin{tabular}{|l|l|}
\hline (A) angry (B) steel (C) necessary (D) aluminium & (E) argument (F) alloy $(G)$ patterns $(H)$ carbon fibre \\
\hline
\end{tabular}

\section{Martini}
(A) alcohol (B) (C) juicy (D) wide
(E) night $(\mathrm{F})$ gin $(\mathrm{G})$ drink $(\mathrm{H})$ smile

20. Water

\begin{tabular}{|c|c|}
\hline (A) full (B) hydrogen (C) Oxygen (D) wide & (E) night $(\mathrm{F})$ liquid $(\mathrm{G})$ fluid $(\mathrm{H})$ smile \\
\hline 21. Road & \\
\hline (A) awake (B) sidewalk (C) knowing (D) laughing & $(\mathrm{E})$ route $(\mathrm{F})$ pavement $(\mathrm{G})$ lane $(\mathrm{H})$ student \\
\hline
\end{tabular}

\section{Salad}
(A) numerical (B)
(B) tomato
(C) lettuce (D) body
(E) liquid (F) cucumber $(\mathrm{G})$ chilli $(\mathrm{H})$ switch

\section{Government}

\begin{tabular}{|l|l|l}
\hline$(A)$ minister $(B)$ constitution $(C)$ coalition $(D)$ clear & $(\mathrm{E})$ help $(\mathrm{F})$ parliament $(\mathrm{G})$ tool $(\mathrm{H})$ approach \\
\hline
\end{tabular}

\section{Organisation}

$\begin{aligned} & \text { (A) short (B) employee (C) quick (D) employer } \\
& \text { 25. Adolescence }\end{aligned}$
\begin{tabular}{l|l|} 
(A) immaturity (B) dating (C) friendship (D) clear & (E) help (F) chatting (G) tool (H) approach \\
\hline
\end{tabular}


26. Shopping

\begin{tabular}{l|l} 
(A) cloudy (B) paying (C) nice (D) entertainment & (E) spending (F) knife (G) purchasing (H) rock
\end{tabular}

27. Eating

\begin{tabular}{|l|l|}
\hline A) easy $(B)$ fresh $(C)$ near $(D)$ chewing & (E) swallow $(F)$ bite $(\mathrm{G})$ munch $(\mathrm{H})$ vegetable \\
\hline
\end{tabular}

28. Desert

\begin{tabular}{|c|c|}
\hline (A) honest (B) oasis (C) dust storm (D) sand & $(\mathrm{E})$ route $(\mathrm{F})$ camel $(\mathrm{G})$ heat $(\mathrm{H})$ river \\
\hline \multicolumn{2}{|l|}{ 29. Country } \\
\hline (A) baseline (B) principal (C) land (D) mountain & (E) scientist $(F)$ sea $(G)$ work $(H)$ producer \\
\hline \multicolumn{2}{|l|}{ 30. World } \\
\hline (A) country (B) bold (C) people (D) upsetting & (E) nature $(\mathrm{F})$ continent $(\mathrm{G})$ problem $(\mathrm{H})$ sleep \\
\hline
\end{tabular}

\section{Appendix 2}

\section{Reading Comprehension Test}

Directions: In this section, you will read several passages. Each one is followed by a number of questions about it. You are to choose the one best answer, (A), $(B),(C)$, or $(D)$, by ticking $(\sqrt{ })$ to each question.

Answer all questions about the information in a passage on the basis of what is stated or implied in that passage.

\section{Text 1}

Read the following texts and answer the following questions:

John Quincy Adams, who served as the sixth president of the United States from 1825 to 1829 , is today recognized for his masterful statesmanship and diplomacy. He dedicated to his life to public service, both in the presidency and in the various other political offices that he held. Throughout his political career he demonstrated his unswerving belief in freedom of speech, the antislavery cause, and the right of Americans to be free from European and Asian domination.

1. In line 4, the word "unswerving" (bold) is closest in meaning to---

(A) moveable

(B) insignificant

(C) unchanging

(D) diplomatic

\section{Text 2}

Carbon tetrachloride is a colorless and inflammable liquid that can be produced by combining carbon disulfide and chlorine. This compound is widely used in industry today because of its effectiveness as a solvent as well as its use in the production of propellants.

Despite the widespread use in industry, carbon tetrachloride has been banned for home use. In the past, carbon tetrachloride was a common ingredient in cleaning compounds that were used throughout the home, but it was found to be dangerous: when heated, it changes into a poisonous gas that can cause severe illness and even death if it is inhaled. Because of this dangerous characteristic, the United States revoked permission for the home use of carbon tetrachloride in 1970.The United States has taken similar action with various other chemical compounds. 
2. The main point of this passage is that

(A) carbon tetrachloride can be very dangerous when it is heated

(B) the government banned carbon tetrachloride in 1970

(C) although carbon tetrachloride can legally be used in industry, it is not allowed in home products

(D) carbon tetrachloride used to be a regular part of cleaning compounds.

3 . The word "widely" (bold) in line 2 could most easily be replaced by
(A) grandly
(B) extensively
(C) largely
(D) hugely

4. The word "banned" (bold) in line 4 is closest in meaning to
(A) forbidden
(B) allowed
(C) suggested
(D) instituted

5. According to the passage, before 1970 carbon tetrachloride was

(A) used by itself as a cleanser

(B) banned in industrial use

(C) often used as a component of cleaning products

(D) not allowed in home cleaning products

6. It is stated in the passage that when carbon tetrachloride is heated, it becomes
(A) harmful
(B) colorless
(C) a cleaning compound
(D) inflammable

7. The word "inhaled" (bold) in line 7 is closest in meaning to---
(A) warmed
(B) breathed in
(C) carelessly used
(D) blown

8. The word "revoked" (bold) in line 8 could most easily be replaced by
(A) gave
(B) granted
(C) instituted
(D) took away

9. It can be inferred from the passage that one role of the U.S. government is to

(A) regulate product safety

(B) prohibit any use of carbon tetrachloride

(C) instruct industry on cleaning methodologies

(D) ban the use of any chemicals

10. The paragraph following the passage most likely discusses

(A) additional uses for carbon tetrachloride

(B) the banning of various chemical compounds by the U.S. government

(C) further dangerous effects of tetrachloride

(D) the major characteristics of carbon tetrachloride 


\section{Text 3}

The next artist in this survey of American artists is James Whistler; he is included in this survey of American artists because he was born in the United States although the majority of his artwork was completed in Europe. Whistler was born in Massachusetts in 1834, but nine years later his father moved the family to St. Petersburg, Russia, to work on the construction of a railroad. The family returned to the United States in 1849. Two years later Whistler entered the U.S. military academy at West Point, but he was unable to graduate. At the age of twenty-one, Whistler went to Europe to study are despite familial objections, and he remained in Europe until his death.

Whistler worked in various art forms, including etchings and lithographs. However, he is most famous for his paintings, particularly Arrangement in Gray and Black No. 1: Portrait of the Artist's Mother or Whistler's Mother as it is more commonly known. This painting shows a side view of Whistler's mother, dressed in black and posing against a gray wall. The asymmetrical nature of the portrait, with his mother seated off-center, is highly characteristic of Whistlers' work.

11. The paragraph preceding this passage most likely discusses

(A) a survey of eighteenth-century art

(B) a different American artist

(C) Whistler's other famous paintings

(D) European artists

12. Which of the following best describes the information in the passages?

(A) Several artists are presented

(B) One artist's life and works are described

(C) Various paintings are contrasted

(D) Whistler's family life is outlined

13. Whistler is considered an American artist because

(A) he was born in America

(B) he spent most of his life in America

(C) he served in the U.S. military

(D) he created most of his famous art in America

14. The word "majority" (bold) in line 2 is closest in meaning to

(A) seniority

(B) maturity

(C) large pieces

(D) high percentage

15. It is implied in the passage that Whistler's family was

(A) unable to find any work at all in Russia

(B) highly supportive of his desire to pursue art

(D) working class

(D) military

16. The word "objections" (bold) in line 7 is closest in meaning to

(A) protests

(B) goals

(C) agreements

(D) battles 
17. In line 9, the "etchings" (bold) are

(A) a type of painting

(B) the same as a lithograph

(C) an art form introduced by Whistler

(D) an art form involving engraving

18. The word "asymmetrical" (bold) in line 13 is closest in meaning to

(A) proportionate

(B) uneven

(C) balanced

(D) lyrical

19. Which of the following is NOT true according to the passage?

(A) Whistler worked with a variety of art forms.

(B) Whistler's Mother is not the official name of his painting.

(C) Whistler is best known for his etchings.

(D) Whistler's Mother is painted in somber tones.

20. Where in the passage does the author mention the types of artwork that Whistler was involved in?
(A) Lines 1-3
(B) Lines 4-5
(C) Lines 6-7
(D) Lines 8-10 